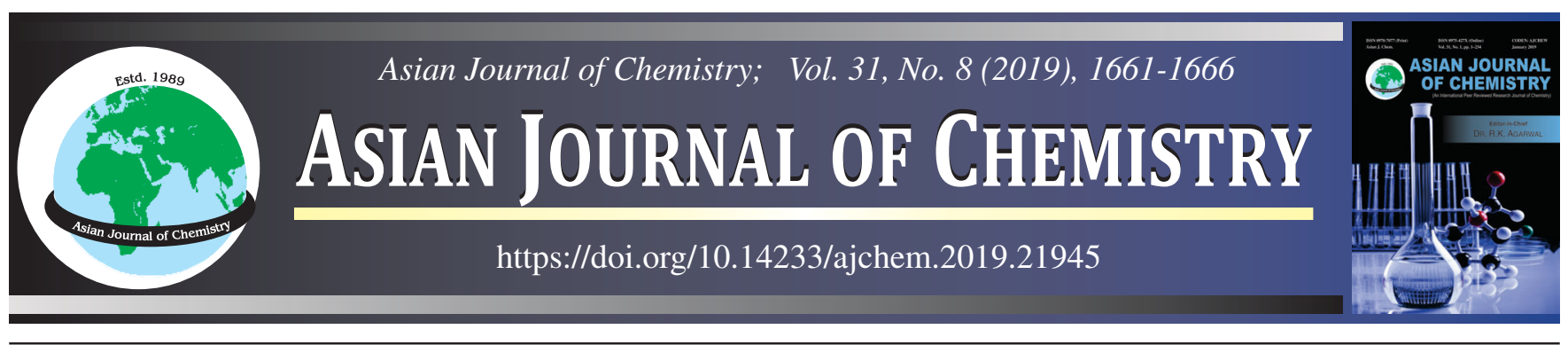

\title{
Synthesis, Growth and Characterization of New Promising Organic \\ Non-Linear Optical Crystal: L-Alanine Alaninium Nitrate
}

\section{G. KRISHNAMOORTHI and R. UVARANI*}

PG and Research Department of Physics, Thiruvalluvar Government Arts College, Rasipuram-637401, India

*Corresponding author: Fax: +91 4287 231882; Tel: +91 4287 231802; E-mail: anbuuvanithin@ gmail.com

\begin{abstract}
A relative study on pure L-alanine alaninium nitrate (LAAN) single crystals and doped with lanthanum oxide, urea and glycine were developed from fluid solution by slow evaporation strategy at room temperature. X-ray diffraction result reveals that LAAN crystallites with system with space bunch P21 and cell parameters $a=7.836 \AA, b=5.428 \AA, c=12.809 \AA$ and $\beta=94.25^{\circ}$. These parameters were marginally changes for doped crystals compared to pure LAAN crystal. The UV results recommend that the great transmission property of the doped LAAN crystal within the whole visible region guarantees its reasonableness for second harmonic generation applications. The presence of dopants within the LAAN crystal was further affirmed through ICP studies. The functional groups were analyzed through Fourier change infrared spectra investigation. The microhardness and dielectric study at $100 \mathrm{~Hz}$ was found to be broadly higher than that of pristine LAAN. The AC conductivity was found to extend after doping due to the induced defects in crystal lattice. The grown crystals were also subjected to second harmonic generation efficiency tests and it was found to be $\mathrm{La}_{2} \mathrm{O}_{3}$ doped LAAN crystal is 2.8 times greater than that of potassium dihydrogen phosphate (KDP).
\end{abstract}

Keywords: Growth from solution, Doping, X-ray diffraction, Non-linear optical material, Dielectric properties.

ᄂ - - - - - - - - - - - - - - - - - - - - - - - - - - - - - - -

\section{INTRODUCTION}

Now-a-days the requirement for non-linear optical materials could be a more than other materials due to their major affect on laser devices, optical communication and optical information capacity gadgets [1]. Organic crystals with huge non-linear optical (NLO) impacts make them dazzling for applications in recurrence transformation and optical handling $[2,3]$. The development of organic materials suitable for nonlinear optical devices is of consideration since of high nonlinearity when compared to that of conventional inorganic materials. Amid organic crystals for non-linear optics (NLO) applications, amino acids show exact highlights of intrigued, such as (i) atomic chirality, which secures centric crystallographic structures, (ii) need of emphatically conjugated bonds, main to wide straightforwardness ranges within the visible and UV spectral region and (iii) zwitter ionic nature of the molecule, which positive in crystals hardness [4,5]. L-alanine crystal (ALA), known due its non-linear optical (NLO) properties [6], is a basic material for the production of a family of semi-organic compounds with orthorhombic non-centrosymmetric structures $\left(\mathrm{P} 2{ }_{1} 2_{1} 2_{1}\right)$ such as: mono-L-alaninium nitrate (MAN) [7], L-alanine hydrogen chloride [8], L-alanine acetate [9], L-alanine sodium nitrate [10] and L-alaninium maleate [11] that have potential applications in NLO. Additionally, the SHG effectiveness of L-alanine is almost one third of potassium dihydrogen phosphate (KDP) but for L-alanine alaninium nitrate (LAAN) is numerous orders of size higher than that of KDP due to the protonation of the amino group. The presence of impurity molecules indeed at lower concentrations within the parent solute may have impressive impact on development energy and other properties. Hence obliging the impact of diverse sorts of impurities on the physical properties of this material needs more examinations. It is well known that lanthanum oxide $\left(\mathrm{La}_{2} \mathrm{O}_{3}\right)$ is well known as ionic substances and are anticipated to exist as ions within the doped crystal. Urea and glycine are curiously natural material having huge dipole moment and capacity to make broad organize of hydrogen bonds. Hence, we have examined the impact of lanthanum oxide, urea and glycine as impurities on the properties of LAAN.

This is an open access journal, and articles are distributed under the terms of the Attribution 4.0 International (CC BY 4.0) License. This license lets others distribute, remix, tweak, and build upon your work, even commercially, as long as they credit the author for the original creation. You must give appropriate credit, provide a link to the license, and indicate if changes were made. 


\section{EXPERIMENTAL}

Crystal growth: L-Alanine alaninium nitrate (LAAN) was synthesized from L-alanine and nitric acid $\left(\mathrm{HNO}_{3}\right)$ taken in the stoichiometric proportion 2:1. The calculated amounts of L-alanine and nitric acid were dissolved in double refined water. In order to synthesize the doped LAAN with (lanthanum oxide, urea, glycine and thiourea), $5 \mathrm{~mol} \%$ of these added substances were included to the solution of LAAN separately. The beaker containing the solution was secured at the best to avoid the vanishing of the solvent. The solutions of pure and doped LAAN were prepared separately and mixed well employing a stirrer for around $2 \mathrm{~h}$. At that point the solution was sifted and exchanged to crystal growth vessels and crystallization was permitted to require put by slow evaporation underneath room temperature. The synthesized salt was then decontaminated by rehashed crystallization. Transparent colourless crystals were collected in a period of 7 days. The photo of the developed crystals is shown in Fig. 1a.

Characterization techniques: X-ray diffraction pattern of all the grown crystals were recorded on Joel JDX 8030 diffractometer (CuKo1 wavelength $1.5406 \AA$ ). Elemental analyses were made by using Perkin-Elmer optima 5300 DV ICP-OES instrument. The optical transmission spectra of LAAN crystals have been recorded in the region 200-1100 nm using a Shimadzu UV-1061 UV-visible spectrometer. The coordination of L-alanine with nitric acid was confirmed by FTIR studies using BRUKER 66V FT-IT spectrometer in the range $4000-400 \mathrm{~cm}^{1}$ following $\mathrm{KBr}$ pellet technique. The photoluminescence spectrum was recorded for LAAN single crystal using Perkin Elmer LS 55 Luminescence spectrometer. The excitation wavelength used for the present study is 390 $\mathrm{nm}$. Dielectric studies were carried out on (010) faces of the grown crystals using Hioki 3532-50 LCR Hitester. Microhardness measurements were carried out using Shimadzu tester. Second harmonic generation (SHG) of the samples was measured by Kurtz powder method. A Q switched Nd:YAG laser beam

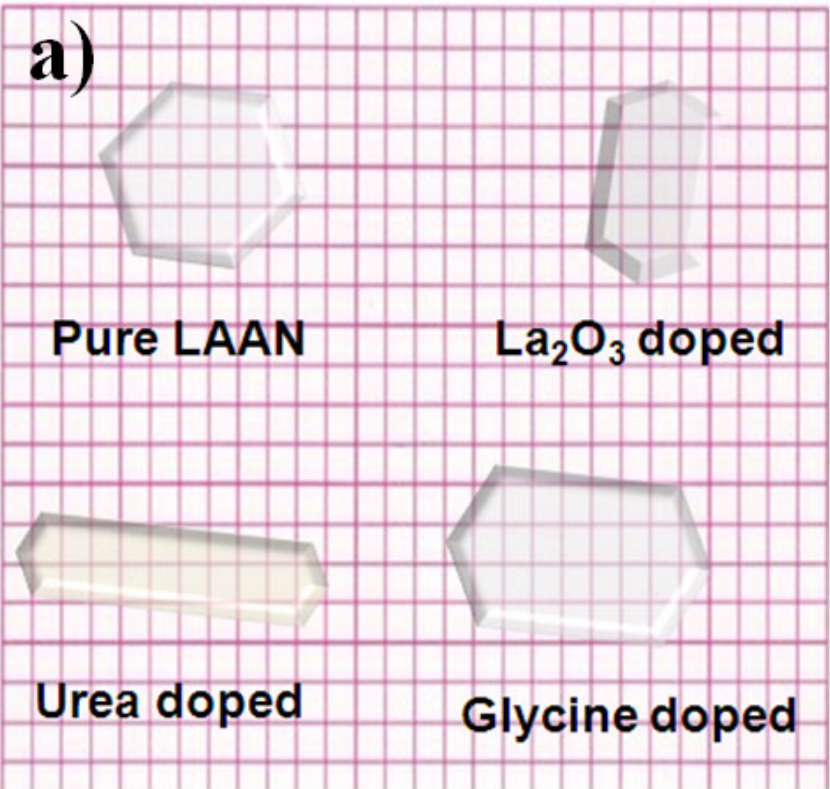

of wavelength $1064 \mathrm{~nm}$ was used within an input energy of $5.02 \mathrm{~mJ} /$ pulse and the pulse width of $8 \mathrm{~ns}$, the depletion rate being $10 \mathrm{~Hz}$. The SHG radiation of $532 \mathrm{~nm}$ (green light) emitted were collected by a photo multiplier tube (PMT-Philips Photonics model 8563) and the optical signal incident on the PMT was converted into voltage output at the CRO (TektonicTDS 3052).

Photocatalytic setup: A specially designed photocatalytic reactor system made of double walled reaction chamber of glass tubes was used for photodegradation experiments. A 300 W xenon lamp as the light source and the control of the reaction bottle of the plane window $20 \mathrm{~cm}$ from the xenon lamp, the reaction using $420 \mathrm{~nm}$ high pass filter to remove the ultraviolet light. The photocatalytic degradation reactions of methylene blue and rhodamine B were considered from the model pollutants. The $50 \mathrm{mg}$ of the prepared photocatalyst was mixed with $50 \mathrm{~mL}$ of aqueous solution containing the appropriate dye (10 $\mathrm{mg} / \mathrm{L}$ for methylene blue and rhodamine B). Prior to reactions, the dye solution with catalysts was stirred in the dark for $30 \mathrm{~min}$ to attain the adsorption, desorption equilibrium. The concentration of the aqueous suspensions (methylene blue and rhodamine B) in each sample was analyzed using UV-visible spectrophotometer at a wavelength of $\lambda_{\max }$. The photocatalytic efficiency was calculated from the expression $\eta=\left(1-\mathrm{C} / \mathrm{C}_{0}\right)$, where $\mathrm{C}_{0}$ is the concentration of dyes (methylene blue and rhodamine $\mathrm{B}$ ) before illumination and $\mathrm{C}$ is the concentration of dyes after a certain irradiation time. The time interval of irradiation time was $20 \mathrm{~min}$.

\section{RESULTS AND DISCUSSION}

ICP and XRD analysis: $10 \mathrm{mg}$ of fine powder of the doped LAAN crystal was broken up in $30 \mathrm{~mL}$ of multiplied refined water and the arranged test was subjected to ICP investigation. The result appears that as it were $2-3 \%$ of $\mathrm{La}^{2+}$, urea and glycine displayed within the test out of $5 \%$ of the dopant. It is seen that the amount of dopant consolidated in to

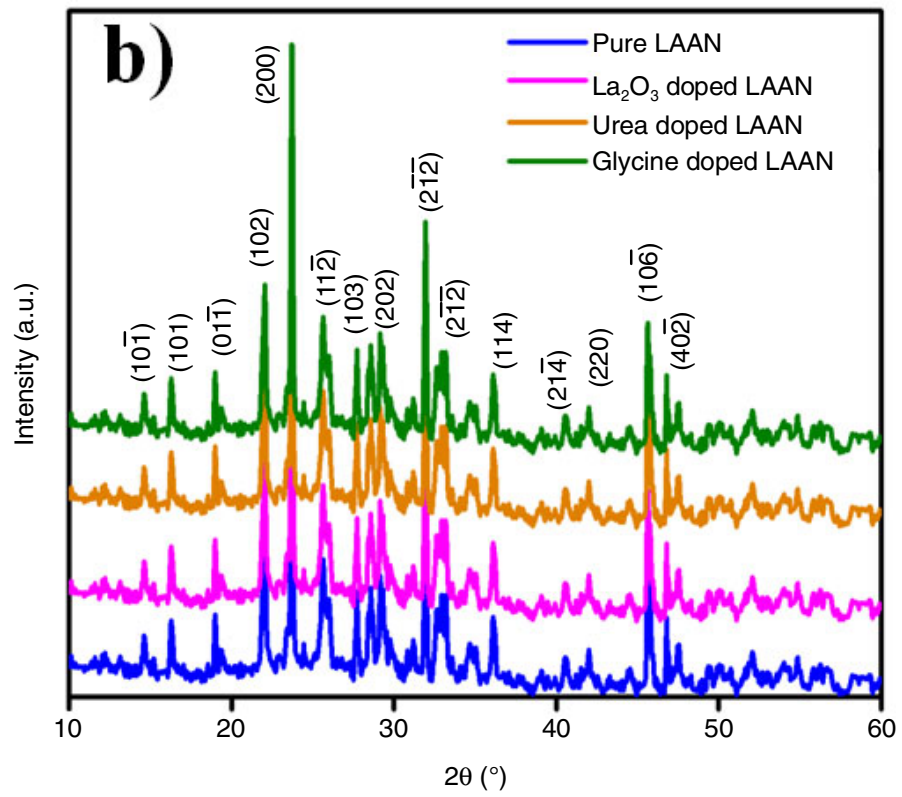

Fig. 1. (a) Photograph of crystals and (b) X-ray diffraction pattern of pure and doped LAAN crystals 
the doped crystal is less than the concentration of the dopant within the corresponding solution. The crystallographic nature of the developed crystals was analyzed through XRD. Fig. 1b shows the XRD pattern of the pure and doped LAAN single crystals. The XRD pattern revealed that the both pure and doped LAAN crystals have a place to monoclinic framework with the space group P21 which is common place as noncentrosymmetric, as a result fulfilling one of the essential and fundamental material necessities for the SHG nature. The results are great agreement with the reported values [12-14]. There is no alter within the crystal structure but the unit cell parameter was marginally changes for doped LAAN crystals (Table-1). This could be due to the presence of impurities may produce lattice strain to pure LAAN crystal [15].

\begin{tabular}{lccccc}
\multicolumn{5}{c}{ TABLE-1 } \\
\multicolumn{5}{c}{ UNIT CELL PARAMETERS OF } \\
\hline \multicolumn{1}{c}{ PURE AND DOPED LAAN CRYSTALS } \\
\hline Pure LAAN & $\mathrm{a}(\AA)$ & $\mathrm{b}(\AA)$ & $\mathrm{c}(\AA)$ & $\beta\left(^{\circ}\right)$ & $\begin{array}{c}\text { Volume } \\
\left(\AA^{3}\right)\end{array}$ \\
$\mathrm{La}_{2} \mathrm{O}_{3}$ doped & 7.845 & 5.428 & 12.809 & 94.05 & 544.81 \\
Urea doped & 7.812 & 5.438 & 12.812 & 95.01 & 546.57 \\
Glycine doped & 7.831 & 5.421 & 12.792 & 94.45 & 540.42 \\
\hline
\end{tabular}

FTIR analysis: The FTIR was recorded in 4000 and 400 $\mathrm{cm}^{-1}$ region is given in Fig. 2. It can be seen that the $\mathrm{OH}$ extending vibration of $\mathrm{COOH}$ gathering create its characteristic peak at $3432 \mathrm{~cm}^{-1}$. The band showed up at $3090 \mathrm{~cm}^{-1}$, is due to $\mathrm{NH}$ stretching vibration of $\mathrm{NH}_{3}$ gather [16]. The absorption of methyl and methane families shows up fair underneath 3000 $\mathrm{cm}^{-1}$. The sharp strongly peaks, which obtained within the range $2120-2110 \mathrm{~cm}^{-1}$ were doled out to the hydrogen holding of $\mathrm{NH}_{3}^{+}$and $\mathrm{COOH}$ group. The peaks within the extend 1595$1590 \mathrm{~cm}^{-1}$ are due to asymmetric COO-vibration. The peaks at $1410 \mathrm{~cm}^{-1}$ is due to $\mathrm{C}-\mathrm{O}$ stretch and the $\mathrm{O}-\mathrm{H}$ twist of $\mathrm{COOH}$ group observed at $1235-1230 \mathrm{~cm}^{-1}$. The arrangement of peaks showed up at 1301,950 and $850 \mathrm{~cm}^{-1}$ is related to $\mathrm{NO}_{3}^{-}$. From

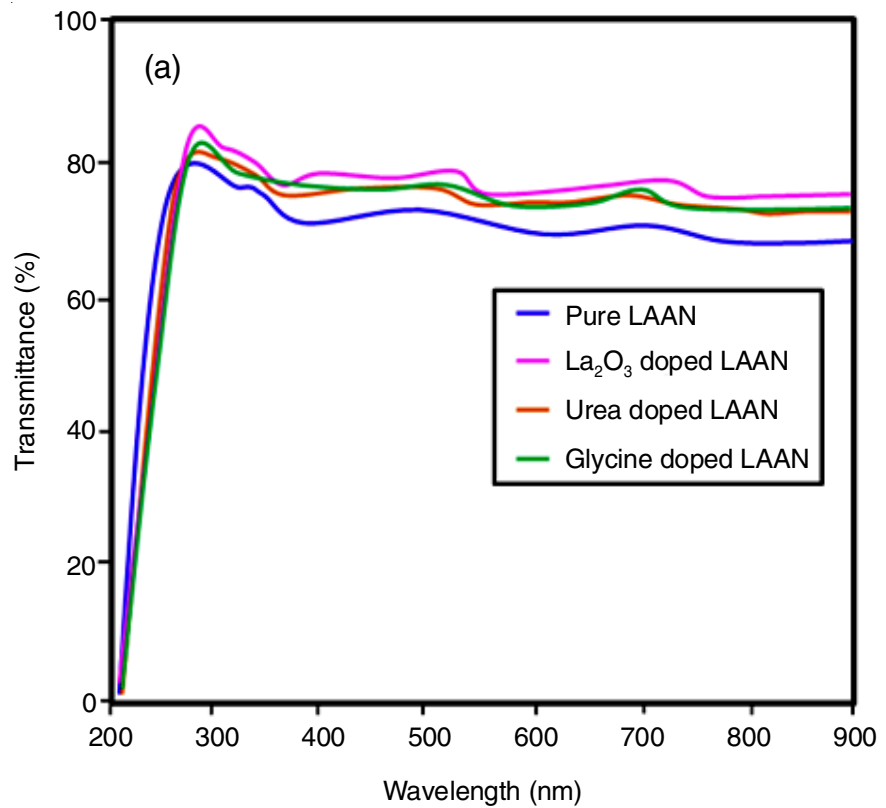

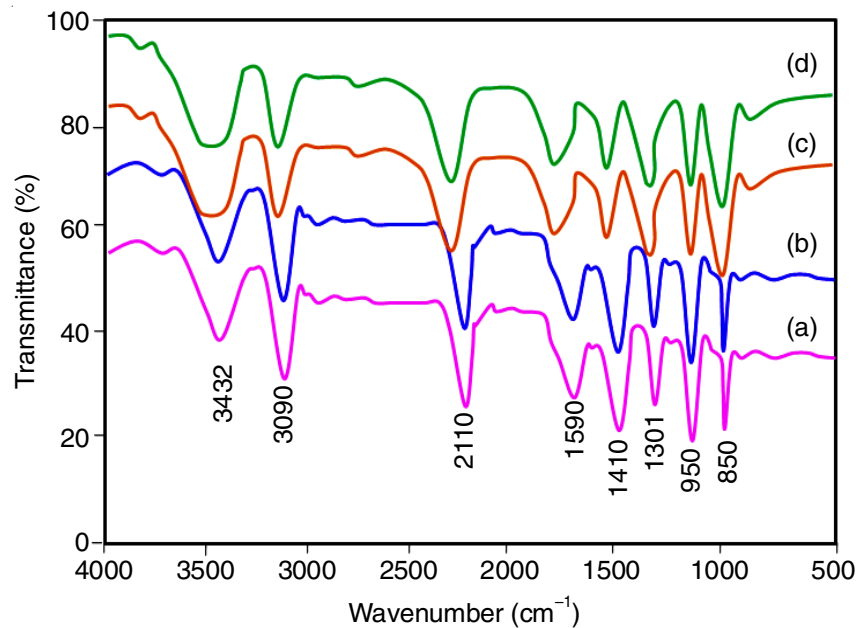

Fig. 2. FTIR spectra of (a) pure LAAN, (b) $\mathrm{La}_{2} \mathrm{O}_{3}$, (c) urea and (d) glycine doped LAAN crystals

the IR spectra, it is clearly that the COO- of pristine and doped LAAN are protonated by nitric corrosive. The comparison of IR spectrums of pure and doped LAAN appears slight move in functional groups, which may be due to doping. The vibrations of pure and doped LAAN are summarized in Table-2.

UV-visible spectra analysis: Fig. 3a shows the transmittance spectra of pure and doped LAAN crystals. From the

\begin{tabular}{ccccl} 
& \multicolumn{4}{c}{ TABLE-2 } \\
& \multicolumn{3}{c}{ VIBRATIONAL ASSIGNMENTS OF } \\
PURE AND DOPED LAAN CRYSTALS \\
\hline Pure & \multicolumn{3}{c}{ Doped with } & \multicolumn{1}{c}{ Vibrations } \\
\cline { 2 - 4 } LAAN & $\mathrm{La}_{2} \mathrm{O}_{3}$ & Urea & Glycine & \multicolumn{1}{c}{} \\
\hline 3432 & 3440 & 3438 & 3430 & $\mathrm{OH}$ stretching \\
3090 & 3095 & 3088 & 3085 & $\mathrm{NH}^{2}$ stretching \\
2110 & 2115 & 2108 & 2102 & $\mathrm{NH}_{3}^{+}$and $\mathrm{COOH}$ group \\
1595 & 1600 & 1596 & 1590 & $\mathrm{COO}^{-}$vibration \\
1410 & 1415 & 1412 & 1408 & $\mathrm{C}^{-O}$ stretching \\
1230 & 1235 & 1228 & 1225 & $\mathrm{COOH}^{\prime}$ stretching \\
950 & 955 & 948 & 945 & $\mathrm{NO}_{3}^{-}$group \\
850 & 856 & 845 & 852 & $\mathrm{NO}_{3}^{-}$group \\
\hline
\end{tabular}

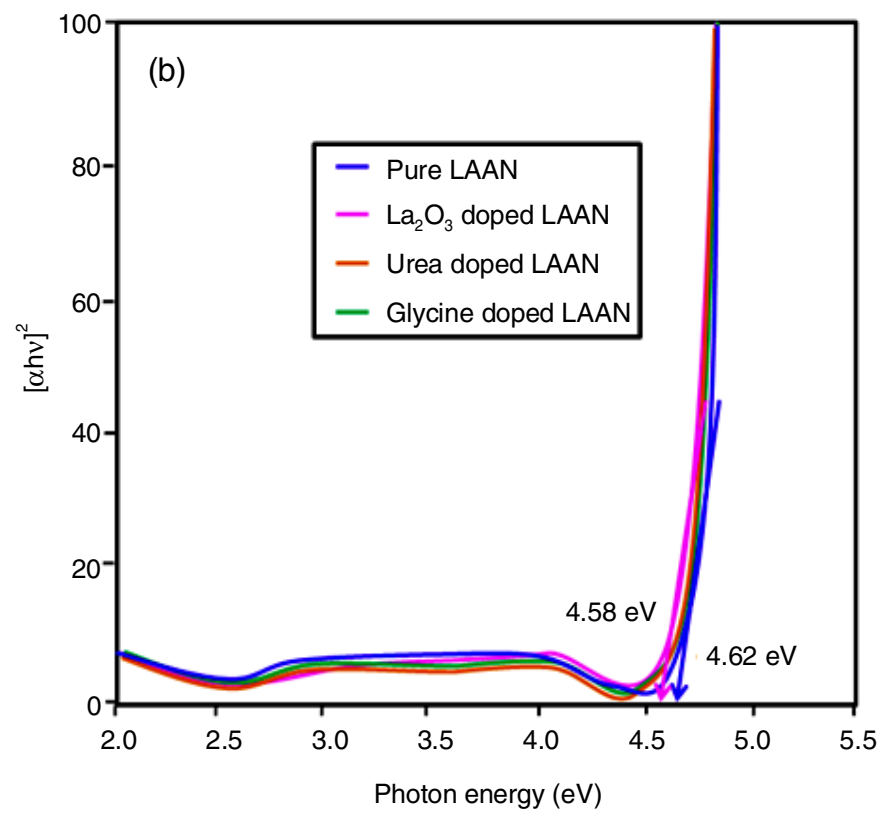

Fig. 3. (a) Transmittance spectra and (b) $(\alpha \mathrm{hv})^{2} v s$. photon energy plot of pure and doped LAAN crystals 
optical transmittance spectra of pure and doped LAAN crystals one can see that there is no change in the transmittance window due to doping and all the crystals have a low UV cut-off in the range of 260-270 $\mathrm{nm}$ The percentages of transmittance in doped samples were found to be more when compared to the pure LAAN. The absorption coefficient $(\alpha)$ and band gap energy of the crystals were calculated by using previous published works [17,18]. The band gap energy was calculated as $4.62,4.58,4.61$ and $4.60 \mathrm{eV}$ for pure LAAN, $\mathrm{La}_{2} \mathrm{O}_{3}$, urea and glycine doped LAAN crystals respectively.

Photoluminescence spectra analysis: The recorded photoluminescence spectra is shown in Fig. 4, in which, the most extreme intensity is obtained around $425 \mathrm{~nm}$ together with low intense peak at $495 \mathrm{~nm}$, which will be due to protonation of amino group to the carboxyl group. After doping, these peaks were assisting diminished. This can be due to recombination of exciton and/or shallow caught electron-hole pairs, which come about in increasing the electrical conductivity of pure LAAN crystal.

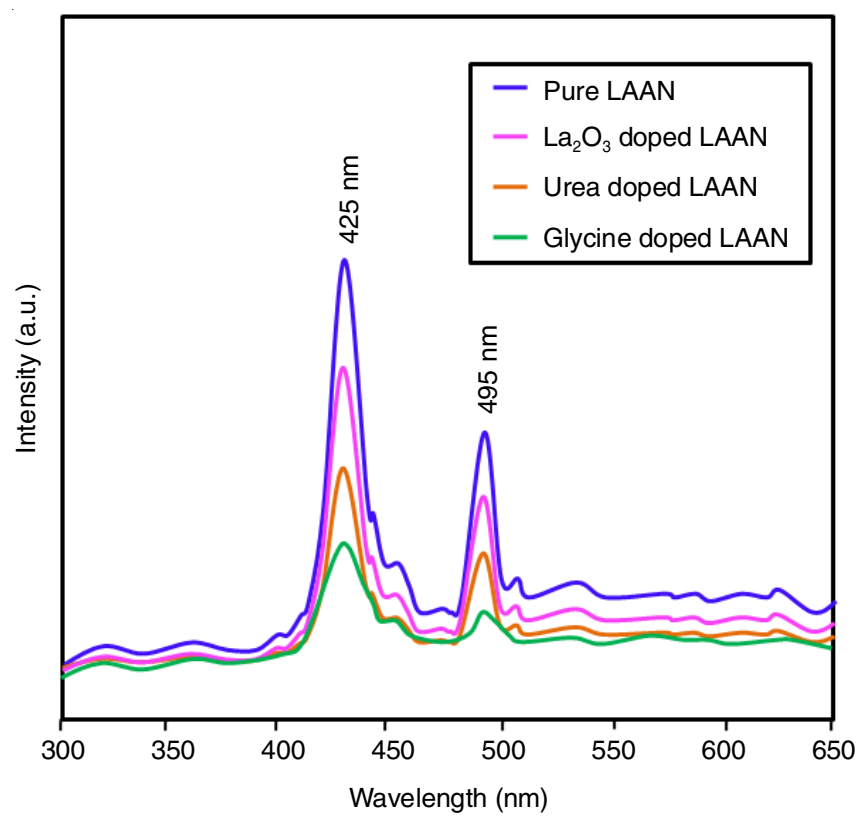

Fig. 4. Photoluminescence spectra of pure and doped LAAN crystals

Microhardness studies: Estimation of hardness could be a valuable nondestructive testing strategy to decide the hardness of the material [19]. Vickers microhardness test was carried out and the graph is shown in Fig. 5. The spaces were made employing a Vickers pyramidal indenter for different loads from 25, 50 and 100g [20]. The result reveals that microhardness values are higher for $\mathrm{La}_{2} \mathrm{O}_{3}$ doped LAAN than pure, urea and glycine doped LAAN crystals. The results recommend that $\mathrm{La}_{2} \mathrm{O}_{3}$ doped LAAN crystals are favoured for device construction than other crystals.

Dielectric studies: A rectangular piece of the crystals were analyzed to dielectric behaviour. The surfaces of the crystals were coated with silver paste to create contact between the crystal and the copper anodes. The capacitance of the test was measured at different frequencies from $100 \mathrm{~Hz}$ to $5 \mathrm{MHz}$ [21]. Fig. 6 appears the plots of dielectric steady versus frequency for all the crystals. It can be seen that as the frequency increments

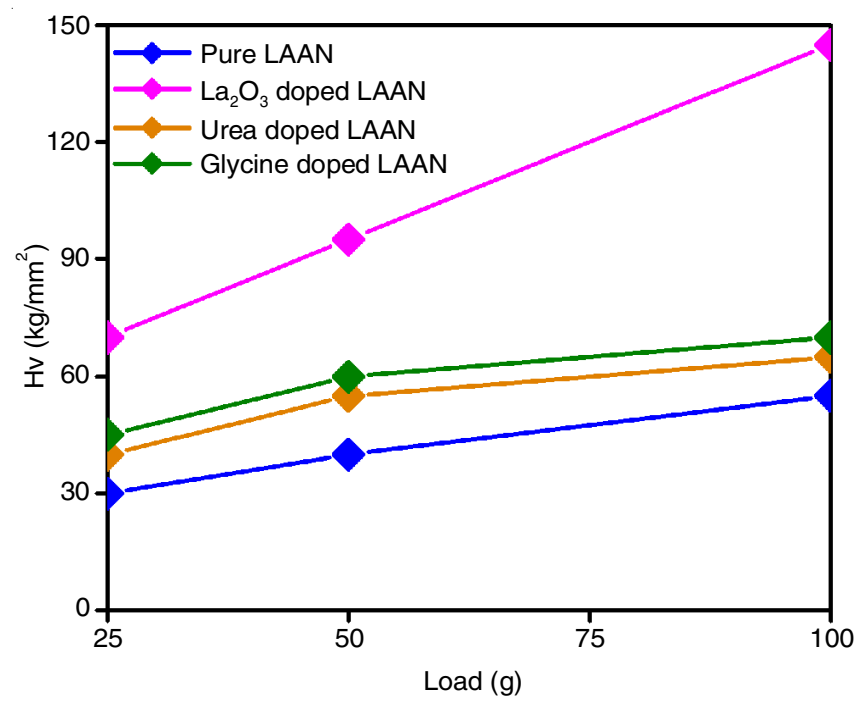

Fig. 5. Vickers hardness vs. load of pure and doped LAAN crystals

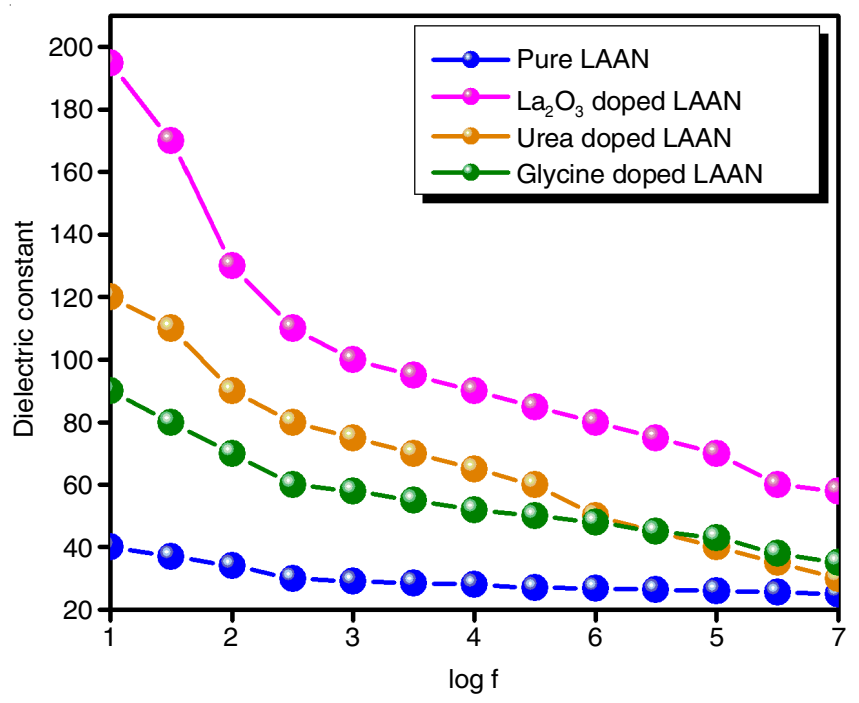

Fig. 6. Dielectric constant vs. $\log$ frequency measured at $40{ }^{\circ} \mathrm{C}$ of pure and doped LAAN crystals

the dielectric steady diminishes and for tall frequency locale it remains nearly consistent for pure and doped LAAN crystals. When the presence of connected electrical areas the number ions within the crystals will trade electronic due to the nearby relocation of the electrons, which in turn is anticipated to deliver rise to the polarization [22]. From the Fig. 6, it can be seen that the dielectric constant of doped crystals are more when compared to pure crystal. The increment in dielectric constant for doped crystals is basically due to the lattice disorder. Fig. 7 appears the variation in dielectric loss tan $\delta$ with frequency. From this figure, it can be seen that the dielectric loss diminishes as the frequency increases for all crystals.

AC conductivity studies: In order to get it the conduction behaviour of pure and doped LAAN crystals, electrical conductivity have been measured in the temperature range of 30 to $90{ }^{\circ} \mathrm{C}$ and the relative graph is shown in Fig. 8. It can be seen that pure LAAN crystal appeared lower electrical conductivity. The AC conductivity of the crystal was found to increase after doping due to the reality that more defects are made after doping. 


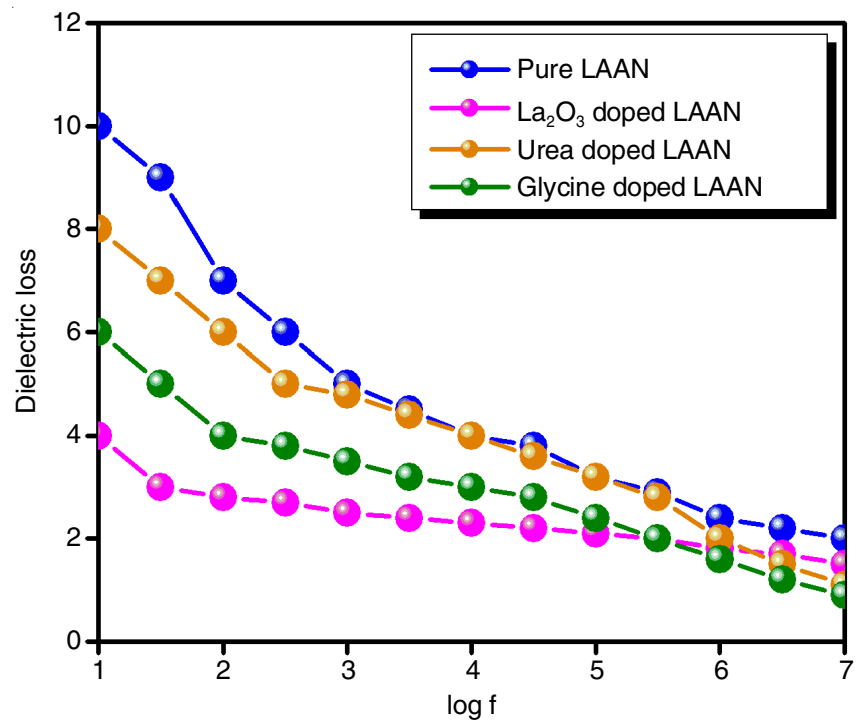

Fig. 7. Dielectric loss $v s . \log$ frequency measured at $40{ }^{\circ} \mathrm{C}$ of pure and doped LAAN crystals

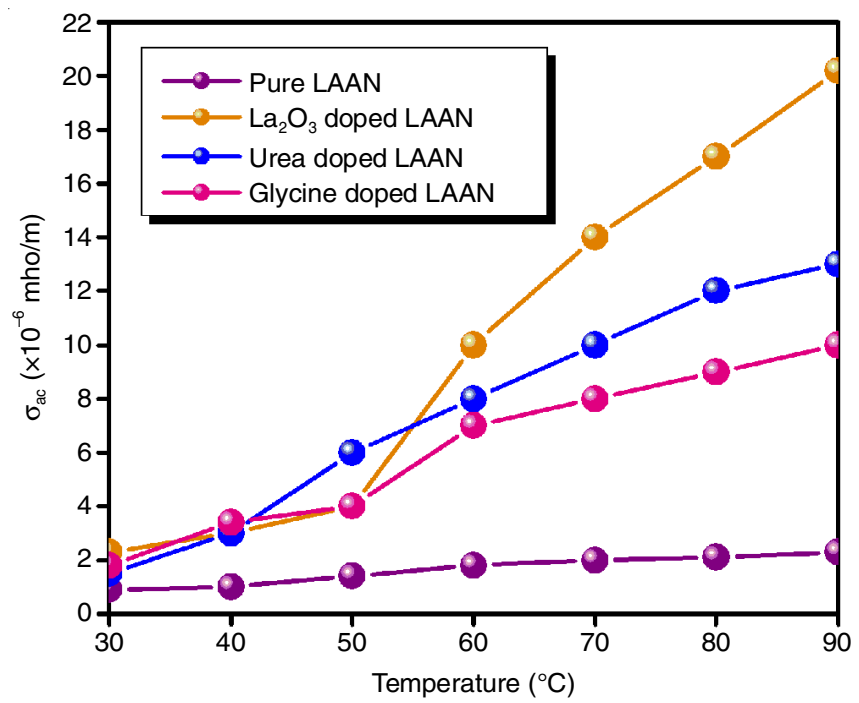

Fig. 8. AC electrical conductivity versus temperature for pure and doped LAAN crystals

The AC conductivity values of all the crystals were examined at room temperature with fixed frequency at $1 \mathrm{kHz}$ are given in Table-3. It was noted that the electrical conductivity was smaller in the lower temperature region for all the crystals, further the conductivity will increase exponentially with temperature and consequently the electrical conduction also increases. Interestingly, the $\mathrm{La}_{2} \mathrm{O}_{3}$ doped LAAN crystal appeared prevalent electrical conductivity than other crystals. The electrical conduction is considered to require put through jumping of electrons. Bouncing conduction is actuated due to the trade of electrons between $\mathrm{La}^{2+}$ ions found at proportionate crystallographic locales. When LAAN crystals were doped with the impurities, the lattice defects increases and this improves the conductivity and hence there is decrease in activation energy [23].

SHG efficiency test: The SHG transformation ability of pure and doped LAAN crystals was evaluated utilizing adjusted setup of Perry and Kurtz [24]. Fig. 10 showed the SHG effectiveness of pure and doped LAAN crystals. The SHG considers

\begin{tabular}{lcc} 
TABLE-3 \\
\multicolumn{3}{c}{ AC CONDUCTIVITY AND ACTIVATION ENERGY } \\
\multicolumn{2}{c}{ VALUES OF THE PURE AND DOPED LAAN CRYSTALS } \\
\hline \multicolumn{1}{c}{ Crystals } & $\begin{array}{c}\text { AC conductivity } \\
(\Omega \mathrm{m})^{-1}\end{array}$ & $\begin{array}{c}\text { Activation energy } \\
(\mathrm{eV})\end{array}$ \\
\hline LAAN & 0.5 & 0.47 \\
$\mathrm{La}_{2} \mathrm{O}_{3}$ doped LAAN & 2.3 & 0.31 \\
Urea doped LAAN & 0.8 & 0.38 \\
Glycine doped LAAN & 2.0 & 0.35 \\
\hline
\end{tabular}

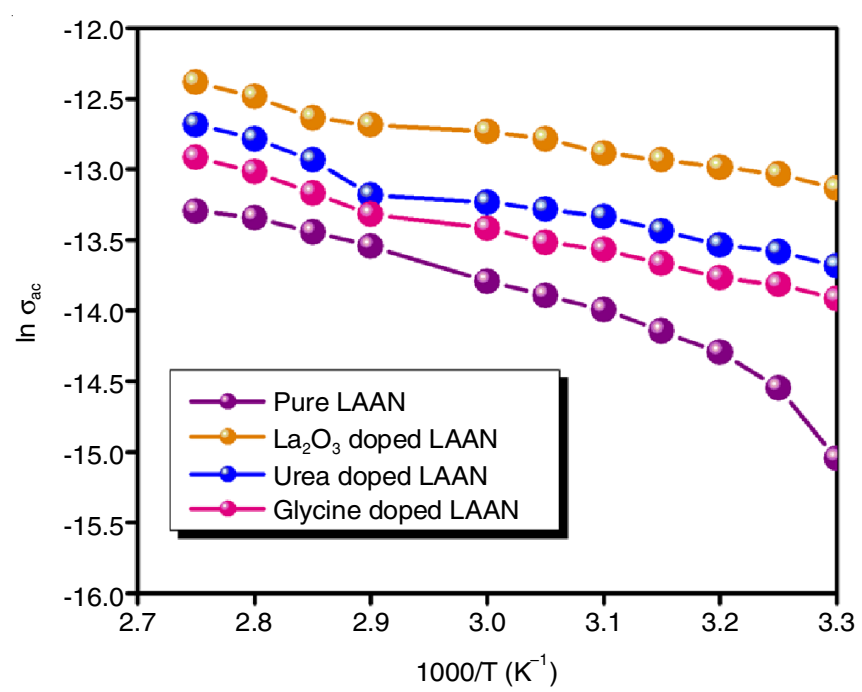

Fig. 9. Variation of $\ln (\sigma)$ with $1000 / \mathrm{T}$ of pure and doped LAAN crystals

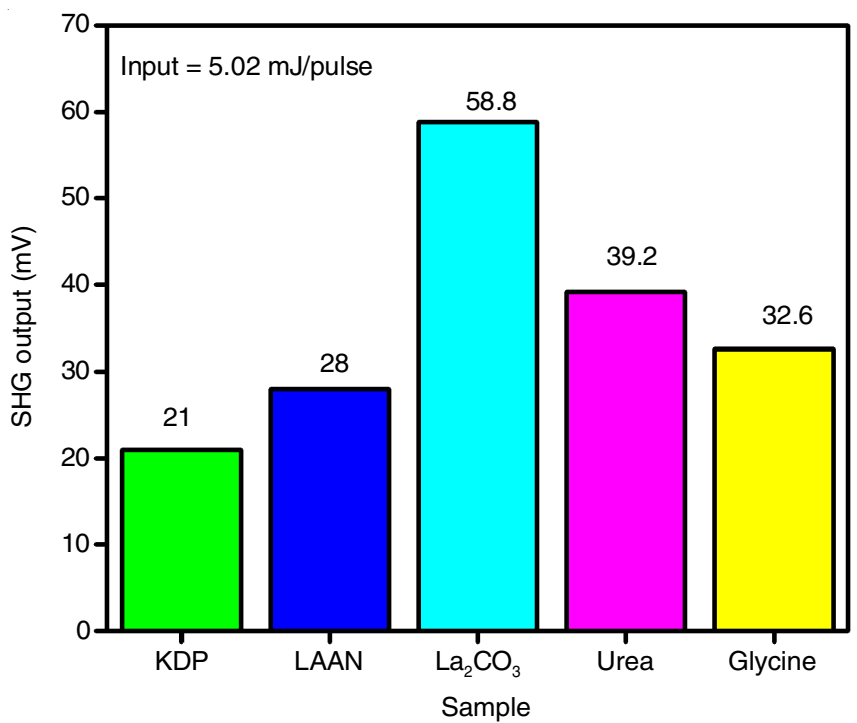

Fig. 10. SHG efficiency of pure and doped LAAN crystals

show that the relative $\mathrm{SHG}$ efficiency of $\mathrm{La}_{2} \mathrm{O}_{3}$ doped LAAN is 2.8 times higher than that of $\mathrm{KDP}$ and 2.1, 1.5 and 1.8 times more prominent than pure, urea and glycine doped LAAN crystals separately. Based on outcomes about we propose that $\mathrm{La}_{2} \mathrm{O}_{3}$ doped LAAN as a novel natural material for NLO applications.

\section{Conclusion}

Single crystals of pure, $\mathrm{La}_{2} \mathrm{O}_{3}$, urea and glycine doped LAAN have been grown by moderate evaporation solution growth strategy at room temperature. XRD results expose that all the crystals have monoclinic structure space group P21. The FTIR 
range affirmed the protonation of the amino group and hence presence of $\mathrm{NO}_{3}{ }^{-}$within the compound. The $\mathrm{UV}$ recommended that the doped LAAN crystals have tall transmittance within the whole visible region for the appropriateness for SHG applications. The microhardness study of the doped crystals demonstrates moderately higher hardness values than the pure LAAN precious stones. The $\mathrm{La}_{2} \mathrm{O}_{3}$ doped LAAN crystal appeared less dielectric loss and high AC conductivity compared to other single crystals. The second harmonic generation property was tested by Kurtz-Perry powder technique and the results showed that the SHG efficiency of $\mathrm{La}_{2} \mathrm{O}_{3}$ doped LAAN crystal is 2.8 times better than pure KDP.

\section{CONFLICT OF INTEREST}

The authors declare that there is no conflict of interests regarding the publication of this article.

\section{REFERENCES}

1. C.B. de Araújo, A.S.L. Gomes and G. Boudebs, Rep. Prog. Phys., 79, 036401 (2016);

https://doi.org/10.1088/0034-4885/79/3/036401.

2. S.R. Mardera, Chem. Commun., 131 (2006); https://doi.org/10.1039/B512646K.

3. J. Badan, R. Hierle, A. Perigaud and J. Zyss, ed.: D.J. Williams, American Chemical Society, Washington, DC (1993).

4. M.L. Caroline, M. Prakash, D. Geetha and S. Vasudevan, Spectrochim. Acta A Mol. Biomol. Spectrosc., 79, 1936 (2011); https://doi.org/10.1016/j.saa.2011.05.094.

5. M.L. Caroline, R. Sankar, R.M. Indirani and S. Vasudevan, Mater. Chem. Phys., 1, 114 (2009).

6. S. Boomadevi and K. Pandiyan, Physica B, 432, 67 (2014); https://doi.org/10.1016/j.physb.2013.09.048.

7. M. Vimalan, X.H. Flora, S. Tamilselvan, R. Jeyasekaran, P. Sagayaraj and C.K. Mahadevan, Arch. Phys. Res., 1, 44 (2010).

8. A.S.J. Lucia Rose, P. Selvarajan and S. Perumal, Mater. Chem. Phys., 130, 950 (2011); https://doi.org/10.1016/j.matchemphys.2011.08.022.
9. J.J. Rodrigues Jr., L. Misoguti, F.D. Nunes, C.R. Mendonca and S.C. Zilio, Opt. Mater., 22, 235 (2003); https://doi.org/10.1016/S0925-3467(02)00270-7.

10. R.M. Kumar, D. Rajan Babu, D. Jayaraman, R. Jayavel and K. Kitamura, J. Cryst. Growth, 275, 1935 (2005); https://doi.org/10.1016/j.jcrysgro.2004.11.260.

11. K. Sethuraman, R. Ramesh Babu, R. Gopalakrishnan and P. Ramasamy, Cryst. Growth Des., 8, 1863 (2008); https://doi.org/10.1021/cg700965d.

12. M.L. Caroline and S. Vasudevan, Mater. Lett., 62, 2245 (2008); https://doi.org/10.1016/j.matlet.2007.11.059.

13. A. Aravindan, P. Srinivasan, N. Vijayan, R. Gopalakrishnan and P. Ramasamy, Spectrochim. Acta A Mol. Biomol. Spectrosc., 71, 297 (2008); https://doi.org/10.1016/j.saa.2007.12.023.

14. A. Aravindan, P. Srinivasan, N. Vijayan, R. Gopalakrishnan and P. Ramasamy, Cryst. Res. Technol., 42, 1097 (2007); https://doi.org/10.1002/crat.200710954.

15. J.G. Arul Raj, P. Selvarajan, S. Perumal and N. Murali Krishnan, Mater. Manuf. Process., 26, 1254 (2011); https://doi.org/10.1080/10426914.2010.544823.

16. R.S. Periathai and K. Rajagopal, IOSR J. Appl. Phys., 6, 9 (2014); https://doi.org/10.9790/4861-06430912.

17. S.S. Roy and J.P. Gilberto, J. Optoelectron. Adv. Mater., 12, 1479 (2010).

18. R.K. Nath, S.S. Nath and K. Sunar, J. Anal. Sci. Technol., 3, 85 (2012); https://doi.org/10.5355/JAST.2012.85.

19. R. Uthrakumar, C. Vesta, C.J. Raj, S. Krishnan and S.J. Das, Curr. Appl. Phys., 10, 548 (2010); https://doi.org/10.1016/j.cap.2009.07.018.

20. R. Parimaladevi, C. Sekar and V. Krishnakumar, Spectrochim. Acta A Mol. Biomol. Spectrosc., 75, 617 (2010); https://doi.org/10.1016/j.saa.2009.11.027.

21. R. Parimaladevi and C. Sekar, Spectrochim. Acta A Mol. Biomol. Spectrosc., 76, 490 (2010); https://doi.org/10.1016/j.saa.2010.04.008.

22. V. Chithambaram, S.J. Das, R.A. Nambi, K. Srinivasan and S. Krishnan, Physica B, 405, 2605 (2010); https://doi.org/10.1016/j.physb.2010.03.004.

23. P. Selvarajan, J. Glorium Arulraj and S. Perumal, Physica B, 405, 738 (2010); https://doi.org/10.1016/j.physb.2009.09.097.

24. S.K. Kurtz and T.T. Perry, J. Appl. Phys., 39, 3798 (1968); https://doi.org/10.1063/1.1656857. 